\title{
Evaluation of bone mineral status in prepuberal children with newly diagnosed type 1 diabetes
}

\author{
Jung Gi Roh, MD', \\ Jong Seo Yoon, MD', \\ Kyu Jung Park, MD', \\ Jung Sub Lim, MD, PhD', \\ Hae Sang Lee, MD, PhD', \\ Jin Soon Hwang, MD, PhD' \\ 'Department of Pediatrics, Ajou \\ University Hospital, Ajou University \\ School of Medicine, Suwon, \\ ${ }^{2}$ Department of Pediatrics, Korea \\ Cancer Center Hospital, Seoul, Korea
}

Purpose: Many studies have reported that patients with type 1 diabetes have reduced bone mineral density (BMD). We assessed bone status in prepubertal children with type 1 diabetes mellitus (type 1 DM) at initial diagnosis and investigated factors associated with BMD.

Methods: Prepubertal children $(n=29)$ with newly diagnosed type 1 diabetes from 2006 to 2014 were included. Dual-energy X-ray absorptiometry measured regional and whole-body composition at initial diagnosis. BMD was compared with healthy controls matched for age, sex, and body mass index (BMI).

Results: The mean age of all subjects ( 16 boys and 13 girls) was $7.58 \pm 1.36$ years (range, 4.8-11.3 years). Initial mean glycosylated hemoglobin $\left(\mathrm{HbA}_{1 \mathrm{c}}\right)$ level was $12.2 \% \pm 1.9 \%$. The mean BMD $z$-scores of lumbar spine, femur neck, and total body were not significantly different between patients and controls. Three patients (10.3\%) had low bone density (total body BMD standard deviation score [SDS] < -2.0). To identify determinants of lumbar spine BMD $z$-score, multivariate regression analysis was performed with stepwise variable selection of age, pubertal status, BMI SDS, insulin like growth factor- 1 , and $\mathrm{HbA}_{1 c^{\circ}}$ Only BMI SDS was significantly correlated with lumbar spine BMD $z$-score $(\beta=0.395, P=0.023)$.

Conclusion: Prepubertal children with newly diagnosed type 1 DM had similar bone mass compared to healthy peers. However, patients with low BMI should be carefully monitored for bone density in type $1 \mathrm{DM}$.

Keywords: Bone mineral density, Type 1 diabetes, Body mass index, Child
Received: 8 April, 2018

Revised: 23 May, 2018

Accepted: 1 June, 2018

Address for correspondence: Hae Sang Lee, MD, PhD

Department of Pediatrics, Ajou University Hospital, Ajou University School of Medicine, 164 World cupro, Yeongtong-gu, Suwon 16499, Korea

Tel: +82-31-219-4454

Fax: +82-31-219-5169

E-mail: seaon98@naver.com

https://orcid.org/0000-0002-96844042

\section{Introduction}

Type 1 diabetes mellitus (T1DM) is an autoimmune disease caused by pancreatic beta cell destruction that usually presents in children and adolescents. Patients with T1DM are at risk for the development of serious complications, such as retinopathy, neuropathy and nephropathy during the disease course. ${ }^{1)}$ Complications associated with diabetes extend to other organ system including the skeletal system in adults. ${ }^{2}$ T1DM is associated with a risk of decreased bone density, even in children and adolescents. ${ }^{3-6)}$

Diabetic complications, age at onset of diabetes, glycemic control and disease duration may affect bone mass in T1DM. However, there is no agreement on the influential clinical determinants of bone density. ${ }^{7}$ Also, insulin is considered an anabolic agent for bone, so decreased insulin secretion before the onset of diabetic symptoms may affect bone status. ${ }^{8)}$ However, most of the previous studies evaluated bone density after diagnosis. There have been few reports on bone mass at initial diagnosis of T1DM in children and adolescents. ${ }^{6,910)}$

The purpose of this study was to evaluate bone mineral density (BMD) in prepubertal children with T1DM at time of initial diagnosis and to investigate the various factors associated with BMD. 


\section{Materials and methods}

\section{Study population}

Of the 85 patients diagnosed as T1DM from August 2007 to June 2014 at Ajou University Hospital, we enrolled 29 prepubertal children who measured BMD. All patients needed to take either conventional or intensive insulin treatment, and none had microalbuminuria, retinopathy and neuropathy at the time of diagnosis. None had a fracture history. Patients with other chronic diseases and metabolic disorders were excluded. Patients who were taking medication to affect bone mineral metabolism, such as glucocorticoid, were excluded. The control group consisted of 92 healthy prepubertal children matched for age, sex, and body mass index (BMI). ${ }^{11}$

\section{Study design}

Patients' height, weight, and pubertal status were collected from the clinical charts and electronic medical records at the time of diagnosis. Height was measured using the Harpenden stadiometer (Holtain, Crosswell, Crymych, UK) and weight was recorded with a digital scale. BMI was calculated as weight divided by height in $\left(\mathrm{kg} / \mathrm{m}^{2}\right)$. Pubertal stage was determined as previously described. ${ }^{12)}$ The prepubertal stage was defined as a lack of breast development in girls and a testicular volume $<3$ $\mathrm{mL}$ in boys. Only prepubertal children were included because sex hormones can affect bone density. The standard deviation score (SDS) for height, weight and BMI were calculated according to the 2007 Korean National Growth Charts. ${ }^{13)}$

Blood samples were obtained for the determination of serum values of calcium, phosphorus, alkaline phosphatase (ALP) and insulin like growth factor-1 (IGF-1). Serum levels of calcium, phosphorus, and ALP was measured using a TBA200FR automatic analyzer (Toshiba, Tokyo, Japan). Glycated hemoglobin $\left(\mathrm{HbA}_{1 \mathrm{c}}\right)$ level was measured with the use of the COBAS Integra 800 turbidimetric inhibition immunoassay (Roche, Basel, Switzerland). Serum IGF-1 levels were measured using the NEXT IRMA CT BC 1110 immunoradiometric assay (Biocode Hycel, Pouilly En Auxois, France). IGF-1 SDS for age and sex was calculated according to Korean IGF-1 levels for the same age and sex in healthy children and adolescents. ${ }^{14)}$

BMD was measured in all patients by dual-energy X-ray absorptiometry within one week after initial diagnosis. Dualenergy X-ray absorptiometry was performed to measure regional and whole-body composition with the Lunar Prodigy device (GE Healthcare, Madison, WI, USA). BMD $\left(\mathrm{g} / \mathrm{cm}^{2}\right)$ at the level of the lumbar spine L1-L4 (LS), femur neck (FN) and total body (TB) were measured by whole-body scan. Subjects were carefully repositioned at every scan to minimize errors associated with changes in measurement geometry by single experienced operator. The coefficients of variation for BMD were $0.339 \%$ (L1-L4), $0.679 \%$ (FN), and $0.454 \%$ (TB). Z-scores of BMD at each site were calculated using data of healthy Korean children and adolescents ( 262 girls and 252 boys) after adjusting for height-for-age. ${ }^{11,15)}$ Low bone density was defined as BMD $z$-scores $<-2$; the low range of normality, between -1 and -2 ; normal BMD was defined as $z$-scores $\geq-1{ }^{16)}$ The study design was reviewed and approved by the Institutional Review Board of Ajou University Hospital (AJIRB-MED-MDB-17-117). Written informed consent by the patients was waived due to a retrospective nature of our study.

\section{Statistical analyses}

Statistical analyses were performed using IBM SPSS Statistics ver. 21.0 (IBM Co., Armonk, NY, USA). An independent $t$-test was used to assess the difference in the mean BMD $z$-scores at lumbar spine, FN and TB between patients and controls. Pearson correlation was examined to determine the relationship between BMD z-scores at each site and other clinical variables. Finding significant association with BMD $z$-scores at each site, linear regression was performed for multivariate analysis with stepwise variable selection, including age at diagnosis, sex, BMI $\mathrm{SDS}, \mathrm{HbA}_{10}$ and IGF-1 levels. Statistical significance was defined as $P<0.05$. Results are described as mean \pm standard deviation unless otherwise stated.

\section{Results}

Clinical characteristics of all patients were shown in Table 1. The mean age of patients was $7.58 \pm 1.36$ years (range, $4.8-11.3$

Table 1. The clinical characteristics of the study and control groups

\begin{tabular}{|c|c|c|c|c|c|c|}
\hline \multirow{2}{*}{ Variable } & \multicolumn{3}{|c|}{ Male } & \multicolumn{3}{|c|}{ Female } \\
\hline & Patients $(n=16)$ & Controls $(n=49)$ & $P$-value & Patients $(n=13)$ & Controls $(n=43)$ & $P$-value \\
\hline Age (yr) & $7.93 \pm 2.44$ & $7.39 \pm 1.39$ & 0.412 & $7.65 \pm 2.37$ & $7.79 \pm 1.31$ & 0.841 \\
\hline Height SDS & $0.22 \pm 0.89$ & $0.26 \pm 0.63$ & 0.827 & $0.51 \pm 0.98$ & $0.17 \pm 0.92$ & 0.246 \\
\hline Weight SDS & $-0.39 \pm 0.98$ & $-0.08 \pm 0.45$ & 0.239 & $-0.33 \pm 1.12$ & $-0.31 \pm 0.69$ & 0.970 \\
\hline BMI SDS & $-0.36 \pm 0.51$ & $-0.72 \pm 1.07$ & 0.217 & $-0.92 \pm 1.14$ & $-0.60 \pm 0.69$ & 0.350 \\
\hline Bone age (yr) & $8.45 \pm 2.93$ & $6.46 \pm 1.36$ & 0.051 & $8.71 \pm 3.11$ & $7.62 \pm 1.78$ & 0.364 \\
\hline $\mathrm{HbA}_{1 c}(\%)$ & $11.76 \pm 1.85$ & - & - & $12.73 \pm 1.93$ & - & - \\
\hline IGF-1 SDS & $-1.38 \pm 1.22$ & - & - & $-1.10 \pm 0.96$ & - & - \\
\hline
\end{tabular}

Values are presented as mean \pm standard deviation.

SDS, standard deviation score; BMI, body mass index; $\mathrm{HbA}_{1 c}$ glycosylated hemoglobin; IGF-1, insulin like growth factor-1. 
years). Seventeen patients (58.6\%) were treated with intensive insulin therapy and $12(41.2 \%)$ were treated with conventional insulin therapy. The mean insulin requirements of all patients were $0.85 \pm 0.25 \mathrm{unit} / \mathrm{kg} / \mathrm{day}$. The initial mean values of $\mathrm{pH}$ and bicarbonate $(\mathrm{mEq} / \mathrm{L})$ were $7.35 \pm 0.1$ and $18.0 \pm 6.2$, respectively. Nine patients (31.0\%) were diagnosed with diabetes ketoacidosis at initial admission. Calcium, phosphorus and ALP levels were within normal limits (data not shown).

Mean BMD $z$-scores of LS, FN, and TB were not significantly different between patients and controls (Table 2). Low bone density $(z$-scores $<-2)$ was found in 3 patients $(10.3 \%)$ at the LS, 4 patients $(13.7 \%)$ at the $\mathrm{FN}$, and 3 patients $(10.3 \%)$ at the TB. Low range of normality ( $z$-scores between -1.0 and -2.0) at LS, FN, and TB were found in $31.0 \%, 10.3 \%$, and $20.6 \%$ of the patients, respectively. When the mean BMD $z$-scores were analyzed depending on sex, there were no significant differences between males and females with T1DM (Table 2). There were no significantly differences between patients with or without diabetic ketoacidosis in the mean BMD $z$-scores (data not shown).

Pearson correlation analysis was performed to investigate the correlation between several variables (age at diagnosis, $\mathrm{HbA}_{1 \mathrm{c}}$, IGF-1 SDS, and BMI SDS) and BMD z-scores. Only BMI SDS was significantly and positively associated with BMD $z$-scores at LS (Fig. 1).

In a stepwise multivariate regression analysis including

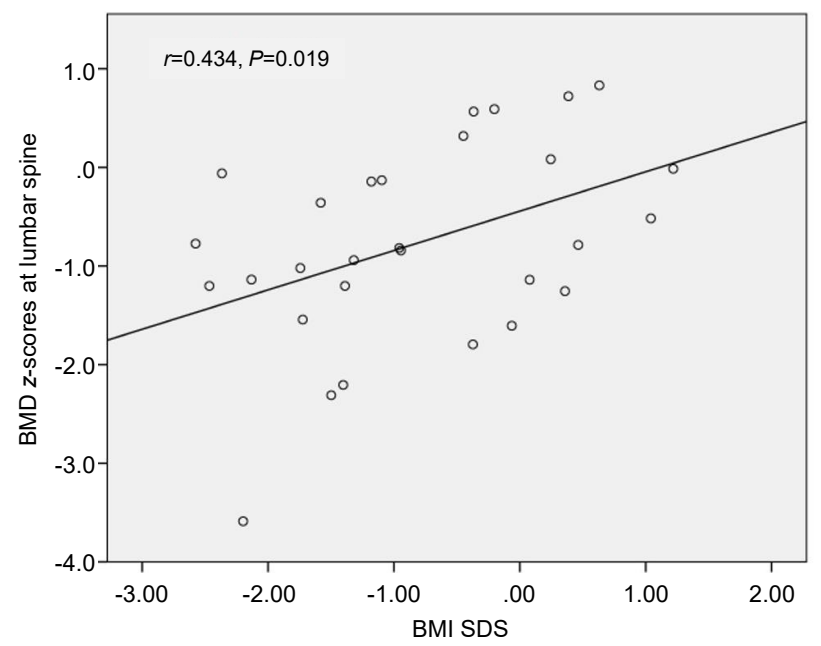

Fig. 1. Correlation between bone mineral density (BMD) at lumbar spine and body mass index standard deviation score (BMI SDS) in patients with type 1 diabetes mellitus. age at diagnosis, sex, BMI SDS, $\mathrm{HbA}_{1 \mathrm{c}}$, and IGF-1 SDS levels as independent variables, and tested in a model with BMD $z$-scores at LS as dependent variable, BMI SDS was identified as significant independent predictors for BMD $z$-scores (Table 3). Age at diagnosis, sex, pubertal status, $\mathrm{HbA}_{1 \mathrm{c}}$ and IGF-1 SDS levels were not significantly related to BMD $z$-scores at LS

\section{Discussion}

Prepubertal children with T1DM did not display significantly lower BMD compared to normal healthy peers at initial diagnosis. BMI SDS was positively correlated with BMD $z$-scores at LS.

Low bone density $(z$-scores $<-2.0)$ and low range of normality $(z$-scores between -1.0 and -2.0) at LS were found in $10.3 \%$ and $31.0 \%$ of the T1DM patients, respectively. Onder et al. ${ }^{17)}$ reported that $35 \%$ of 100 pediatric patients with T1DM showed abnormality of LS BMD ( $z$-scores $<-1.0)$, similar to our study. In other studies about children and adolescents, the proportion of Z-scores < - 1 at LS ranged from $26.7 \%$ to $45.4 \%{ }^{9,10,18,19)}$ In prior studies, most children and adolescents with T1DM displayed significantly lower BMD at one or multiple skeletal sites, although a few studies detected no difference in BMD $z$-scores between T1DM patients and healthy controls. ${ }^{7,20)}$ Most previous studies evaluated bone density after diagnosis and disease had progressed. A few studies addressed BMD in T1DM at initial diagnosis or early in the disease course. The strength of our study was the measurement of bone density at time of diagnosis in prepubertal children. Presently, LS BMD $z$-scores at initial diagnosis were $-0.76 \pm 1.00$ and scores were lower than zero. However, no significant difference between patients and healthy controls was evident. Gunczler et al. ${ }^{10)}$ studied BMD at a mean of $5.8 \pm 1.5$ months after diagnosis in 23 prepubertal children with T1DM. LS BMD $z$-scores were decreased compared to normal controls. Camurdan et al. ${ }^{9)}$ reported that LS BMD $z$-scores of 16 patients with newly diagnosed T1DM were lower

Table 3. Multivariate analysis of factors associated with bone mineral density at lumbar spine $\left(n=29, r^{2}=0.185, P=0.023\right)$

\begin{tabular}{lccc}
\hline Variable & Estimate & SE & $P$-value \\
\hline BMI SDS & 0.395 & 0.163 & 0.023 \\
\hline SE, Standard
\end{tabular}

SE, standard error; BMI SDS, body mass index standard deviation score; $\mathrm{HbA}_{1 \mathrm{c}}$ glycosylated hemoglobin; IGF-1, insulin like growth factor-1.

Stepwise multivariate regression analysis contained the following independent variables entered in to the model: age at diagnosis, BMI SDS, $\mathrm{HbA}_{1 \mathrm{c}}$ and IGF-1 levels.

Table 2. Bone mineral density $z$-scores of lumbar spine, femur neck, and total body between patients and controls and in patients divided by sex

\begin{tabular}{lcccccc}
\hline Variable & Patients $(n=29)$ & Controls $(n=92)$ & $P$-value & Male patients $(n=16)$ & Female patients $(n=13)$ & $P$-value \\
\hline Lumbar spine & $-0.76 \pm 1.00$ & $-0.43 \pm 0.85$ & 0.083 & $-0.67 \pm 0.86$ & $-0.88 \pm 1.17$ & 0.583 \\
Femur neck & $-0.45 \pm 1.11$ & $-0.27 \pm 0.87$ & 0.226 & $-0.59 \pm 1.10$ & $-0.33 \pm 1.14$ & 0.544 \\
Total body & $-1.17 \pm 3.87$ & $-0.46 \pm 0.85$ & 0.335 & $-0.12 \pm 0.98$ & $-0.91 \pm 1.36$ & 0.089 \\
\hline
\end{tabular}

Values are presented as mean \pm standard deviation. 
than zero $(-0.49 \pm 0.97)$, but were statistically insignificant. In adults, LS BMD $z$-scores of 32 adult-onset T1DM patients at the time of diagnosis were $-0.61 \pm 1.23$ and were significantly lower than a matched normal population in. ${ }^{21)}$

The underlying mechanisms of reduced bone density in T1DM are not fully known and no single mechanism can explain the effect of T1DM on BMD. ${ }^{22)}$ Insulin deficiency and hyperglycemia are well known characteristics of T1DM. Low insulin levels may be crucial for low bone density. ${ }^{23,24)}$ Insulin replacement in rats with diabetes has been shown to normalize bone turnover. ${ }^{25)}$ Hyperglycemia also suppresses osteoblastic differentiation and signaling, potentially resulting in decreased bone formation. ${ }^{26)}$ So, we hypothesized that patients with newly diagnosed T1DM would have lower BMD compared to their healthy peers. However, our results showed that BMD $z$-scores were not reduced at the early course of the disease. Also, insulin and hyperglycemia were not only the crucial role of decreased bone density in T1DM. Other factors, such as IGF-1 level, incretin and inflammation, can affect bone formation and resorption. ${ }^{27)}$ Especially, bone health could be more vulnerable in those who develop T1DM earlier in their lives because childhood and adolescence are critical periods for skeletal development. $^{28)}$

There have been variable factors that are associated with decreased bone mineralization in type 1 DM. In present study, low BMI was significantly correlated with low BMD. Low BMI is associated with low BMD. ${ }^{29)}$ Neumann et al. ${ }^{30)}$ reported that low BMI is a predictor of low BMD in women with T1DM. In another study, LS and FN BMD were independently correlated with BMI in adults with T1DM. ${ }^{31)}$ These studies suggest that body composition and lean body mass may affect the bone density in people T1DM. In addition to BMI, IGF-1 levels, bone size, disease duration, glycemic control, age and sex have been associated with reduced bone density., ${ }^{40-34)}$ But the clinical determinants of bone health in T1DM remain debatable.

The current study had several limitations. First, the crosssectional analysis did not allow the assessment of causality. Second, we did not evaluate bone resorption and formation markers, such as osteocalcin. Third, we did not investigate vitamin D, PTH, hypercalciuria, and physical activity, which are known to be associated with bone health. Fourth, the sample size was relatively small. Finally, the duration of hyperglycemia and insulin deficiency of patients with T1DM may be short enough to affect bone health. Therefore, a long-term study involving a larger cohort is required to investigate the pathogenesis of low BMD and related factors in children and adolescents with T1DM.

In conclusion, prepubertal children with T1DM had similar bone density compared to healthy controls at time of initial diagnosis. Low BMI was the only predictor of decreased BMD. Based on our results, type 1 DM patients with low BMI should be carefully monitored about bone density, although the screening of bone status at initial diagnosis in all children with T1DM may not be necessary.

\section{Conflict of interest}

No potential conflict of interest relevant to this article was reported.

\section{References}

1. Eisenbarth GS. Update in type 1 diabetes. J Clin Endocrinol Metab 2007;92:2403-7.

2. Vestergaard P. Discrepancies in bone mineral density and fracture risk in patients with type 1 and type 2 diabetes: a meta-analysis. Osteoporos Int 2007;18:427-44.

3. Bachrach LK, Gordon CM; Section on Endocrinology. Bone densitometry in children and adolescents. Pediatrics 2016;138(4). pii: e20162398.

4. Léger J, Marinovic D, Alberti C, Dorgeret S, Chevenne D, Marchal CL, et al. Lower bone mineral content in children with type 1 diabetes mellitus is linked to female sex, low insulin-like growth factor type I levels, and high insulin requirement. J Clin Endocrinol Metab 2006;91:3947-53.

5. Karagüzel G, Akçurin S, Ozdem S, Boz A, Bircan I. Bone mineral density and alterations of bone metabolism in children and adolescents with type 1 diabetes mellitus. J Pediatr Endocrinol Metab 2006;19:805-14.

6. Moyer-Mileur LJ, Dixon SB, Quick JL, Askew EW, Murray MA. Bone mineral acquisition in adolescents with type 1 diabetes. J Pediatr 2004;145:662-9.

7. Pan H, Wu N, Yang T, He W. Association between bone mineral density and type 1 diabetes mellitus: a metaanalysis of cross-sectional studies. Diabetes Metab Res Rev 2014;30:531-42.

8. Fowlkes JL, Bunn R C, Thrailkill KM. Contributions of the insulin/insulin-like growth factor-1 axis to diabetic osteopathy. J Diabetes Metab 2011;1(3). pii: S1-003.

9. Camurdan MO, Ciaz P, Bideci A, Demirel F. Role of hemoglobin $\mathrm{A}(1 \mathrm{c})$, duration and puberty on bone mineral density in diabetic children. Pediatr Int 2007;49:645-51.

10. Gunczler P, Lanes R, Paoli M, Martinis R, Villaroel O, Weisinger JR. Decreased bone mineral density and bone formation markers shortly after diagnosis of clinical type 1 diabetes mellitus. J Pediatr Endocrinol Metab 2001;14:5258.

11. Lim JS, Hwang JS, Lee JA, Kim DH, Park KD, Cheon GJ, et al. Bone mineral density according to age, bone age, and pubertal stages in korean children and adolescents. J Clin Densitom 2010;13:68-76.

12. Marshall WA, Tanner JM. Variations in the pattern of pubertal changes in boys. Arch Dis Child 1970;45:13-23.

13. Moon JS, Lee SY, Nam CM, Choi JM, Choe BK, Seo JW, et al. 2007 Korean National Growth Charts: review of developmental process and an outlook. Korean J Pediatr 2008;51:1-25.

14. Song AK, Kim HJ, Suk HJ, Hwang JS, Hong CH. Serum IGF-I and IGFBP-3 in 919 healthy Korean children and 
adolescents: normal values and correlations with age, sex, height, body mass index and bone age. J Korean Soc Pediatr Endocrinol 2005; 10:35-41.

15. Zemel BS, Leonard MB, Kelly A, Lappe JM, Gilsanz V, Oberfield S, et al. Height adjustment in assessing dual energy x-ray absorptiometry measurements of bone mass and density in children. J Clin Endocrinol Metab 2010;95:1265-73.

16. Shaw NJ. Management of osteoporosis in children. Eur J Endocrinol 2008;159 Suppl 1:S33-9.

17. Onder A, Cetinkaya S, Tunc O, Aycan Z. Evaluation of bone mineral density in children with type 1 diabetes mellitus. J Pediatr Endocrinol Metab 2013;26:1077-81.

18. Mosso C, Hodgson MI, Ortiz T, Reyes ML. Bone mineral density in young Chilean patients with type 1 diabetes mellitus. J Pediatr Endocrinol Metab 2016;29:731-6.

19. Valerio G, del Puente A, Esposito-del Puente A, Buono P, Mozzillo E, Franzese A. The lumbar bone mineral density is affected by long-term poor metabolic control in adolescents with type 1 diabetes mellitus. Horm Res 2002;58:266-72.

20. Weber DR, Schwartz G. Epidemiology of skeletal health in type 1 diabetes. Curr Osteoporos Rep 2016;14:327-36.

21. López-Ibarra PJ, Pastor MM, Escobar-Jiménez F, Pardo MD, González AG, Luna JD, et al. Bone mineral density at time of clinical diagnosis of adult-onset type 1 diabetes mellitus. Endocr Pract 2001;7:346-51.

22. Napoli N, Chandran M, Pierroz DD, Abrahamsen B, Schwartz AV, Ferrari SL, et al. Mechanisms of diabetes mellitus-induced bone fragility. Nat Rev Endocrinol 2017;13:208-19.

23. Bouillon R, Bex M, Van Herck E, Laureys J, Dooms L, Lesaffre E, et al. Influence of age, sex, and insulin on osteoblast function: osteoblast dysfunction in diabetes mellitus. J Clin Endocrinol Metab 1995;80:1194-202.

24. Bouillon R. Diabetic bone disease. Calcif Tissue Int 1991;49:155-60.

25. Verhaeghe J, Suiker AM, Visser WJ, Van Herck E, Van Bree $\mathrm{R}$, Bouillon R. The effects of systemic insulin, insulin-like growth factor-I and growth hormone on bone growth and turnover in spontaneously diabetic BB rats. J Endocrinol 1992; 134:485-92.

26. Botolin S, McCabe LR. Chronic hyperglycemia modulates osteoblast gene expression through osmotic and nonosmotic pathways. J Cell Biochem 2006;99:411-24.

27. Hough FS, Pierroz DD, Cooper C, Ferrari SL; IOF CSA Bone and Diabetes Working Group. Mechanisms in endocrinology: mechanisms and evaluation of bone fragility in type 1 diabetes mellitus. Eur J Endocrinol 2016;174:R127-38.

28. Williams KM. Update on bone health in pediatric chronic disease. Endocrinol Metab Clin North Am 2016;45:433-41.

29. Bianchi ML, Leonard MB, Bechtold S, Högler W, Mughal MZ, Schönau E, et al. Bone health in children and adolescents with chronic diseases that may affect the skeleton: the 2013 ISCD Pediatric Official Positions. J Clin Densitom 2014;17:281-94.

30. Neumann T, Sämann A, Lodes S, Kästner B, Franke $\mathrm{S}$, Kiehntopf $\mathrm{M}$, et al. Glycaemic control is positively associated with prevalent fractures but not with bone mineral density in patients with Type 1 diabetes. Diabet Med 2011;28:872-5.

31. Eller-Vainicher C, Zhukouskaya VV, Tolkachev YV, Koritko SS, Cairoli E, Grossi E, et al. Low bone mineral density and its predictors in type 1 diabetic patients evaluated by the classic statistics and artificial neural network analysis. Diabetes Care 2011;34:2186-91.

32. Zhukouskaya VV, Eller-Vainicher C, Shepelkevich AP, Dydyshko Y, Cairoli E, Chiodini I. Bone health in type 1 diabetes: focus on evaluation and treatment in clinical practice. J Endocrinol Invest 2015;38:941-50.

33. AboElAsrar MA, Elbarbary NS, Elshennawy DE, Omar AM. Insulin-like growth factor- 1 cytokines cross-talk in type 1 diabetes mellitus: relationship to microvascular complications and bone mineral density. Cytokine 2012;59:86-93.

34. Mastrandrea LD, Wactawski-Wende J, Donahue RP, Hovey KM, Clark A, Quattrin T. Young women with type 1 diabetes have lower bone mineral density that persists over time. Diabetes Care 2008;31:1729-35. 